\title{
Lead ions removal from aqueous solution using modified carbon nanotubes
}

\author{
NGUYEN DUC VU QUYEN ${ }^{1, *}$, TRAN NGOC TUYEN ${ }^{1}$, DINH QUANG KHIEU ${ }^{1}$, \\ HO VAN MINH HAI ${ }^{1}$, DANG XUAN TIN ${ }^{1}$, PHAM THI NGOC LAN ${ }^{2}$ and ITATANI KIYOSHI \\ ${ }^{1}$ Chemistry Department, College of Sciences, Hue University, Hue City 530000, Vietnam \\ ${ }^{2}$ Transportation Community College, Danang City 550000, Vietnam \\ ${ }^{3}$ Department of Materials and Life Sciences, Faculty of Science and Technology, Sophia University, \\ Tokyo 102-0094, Japan \\ *Author for correspondence (vuquyen2702@gmail.com)
}

MS received 1 February 2017; accepted 3 May 2017; published online 2 February 2018

\begin{abstract}
Surface-modified carbon nanotubes (CNTs) were prepared in order to remove lead ions $\left(\mathrm{Pb}^{2+}\right)$ from aqueous solution. The modification of CNTs was conducted by oxidation, using a mixture of nitric acid $\left(\mathrm{HNO}_{3}\right)$ and sulphuric acid $\left(\mathrm{H}_{2} \mathrm{SO}_{4}\right)$. The adsorption behaviour was well fitted to the Langmuir model and the maximum adsorption capacity of $\mathrm{Pb}^{2+}$ was found to be $100 \mathrm{mg} \mathrm{g}^{-1}$. The adsorption of $\mathrm{Pb}^{2+}$ reached equilibrium in $80 \mathrm{~min}$. The experimental data were well fitted to a pseudo-second-order rate model rather than a pseudo-first-order model. The activation energy and activation enthalpy of the adsorption calculated from Arrhenius and Eyring equations were, respectively, 21.08 and $18.56 \mathrm{~kJ} \mathrm{~mol}^{-1}$, which reflect the outside surface adsorption and ion exchange mechanism. The thermodynamical studies showed that the adsorption of $\mathrm{Pb}^{2+}$ was a spontaneous and endothermic process. The ion exchange mechanism of $\mathrm{Pb}^{2+}$ removal was confirmed by the $\mathrm{pH}$ and electrical conductivity data in solution before and after adsorption.
\end{abstract}

Keywords. Carbon nanotubes; surface modification; lead ions removal; surface-modified carbon nanotubes.

\section{Introduction}

Recently, in Vietnam and many other countries, the pollution of water by inorganic and organic compounds has increased with the development of industry. The presence of heavy metal ions in water, including copper $\left(\mathrm{Cu}^{2+}\right)$, lead $\left(\mathrm{Pb}^{2+}\right)$, cadmium $\left(\mathrm{Cd}^{2+}\right)$, zinc $\left(\mathrm{Zn}^{2+}\right)$ and chromium $\left(\mathrm{Cr}^{3+}\right)$, may be a potential hazard to human health $[1,2]$. Among such metal ions, lead ions $\left(\mathrm{Pb}^{2+}\right)$ are a noted contaminant that can cause numerous health problems when accumulated in the human body for a long time.

The carbon nanotubes (CNTs) are known to possess excellent adsorption behaviour against heavy metals [3-6], but the agglomeration nature of CNTs restricts the effective surface areas of CNTs for the adsorption of heavy metals. The excellent adsorption behaviour of CNTs may be remarkably enhanced by the surface modification that increases the effective surface area, e.g., the utilization of some oxidants, such as $\mathrm{HNO}_{3}, \mathrm{H}_{2} \mathrm{SO}_{4}, \mathrm{KMnO}_{4} \mathrm{H}_{2} \mathrm{O}_{2}$ or $\mathrm{NaClO}$ [7-9]. Additionally, the acid treatment of CNTs plays an important role in (i) the enhanced dispersion in water or solvents that may depend on the amount of polar functional groups, e.g., $-\mathrm{OH},-\mathrm{C}=\mathrm{O}$ and $-\mathrm{COOH}[10-12]$ and (ii) the removals of not only impurities such as metals or metal oxides (catalysts) used for the preparation of CNTs but also byproducts (e.g., amorphous carbon) [13-15]. Further, the electrostatic charge that is derived from such polar functional groups causes attraction forces of metal ions, thereby enhancing the adsorption of heavy metals. The amounts of such functional groups may be varied, depending on the oxidant concentration and modification temperature/time [16]. In some cases, the oxidation is utilized as the first step to functionalize the surface of CNTs by the additional groups like amines [17].

Regarding the removal of $\mathrm{Pb}^{2+}$ ions by CNTs, many studies conducted so far showed the values of maximum $\mathrm{Pb}^{2+}$ adsorption capacity to be still comparatively low [18-21], regardless of the useful proposals of ion exchange technique or adsorption mechanism of the $\mathrm{Pb}^{2+}$ ions in aqueous solution. In this study, the modification conditions of CNTs surfaces suitable for the adsorption of $\mathrm{Pb}^{2+}$ in the aqueous solution are examined, together with the ion exchange and adsorption mechanism.

\section{Experimental}

\subsection{Materials}

The starting CNTs were synthesized from liquid petroleum gas (LPG) by the chemical vapour deposition (CVD) method, in which LPG carried in a nitrogen flow was pyrolysed at 


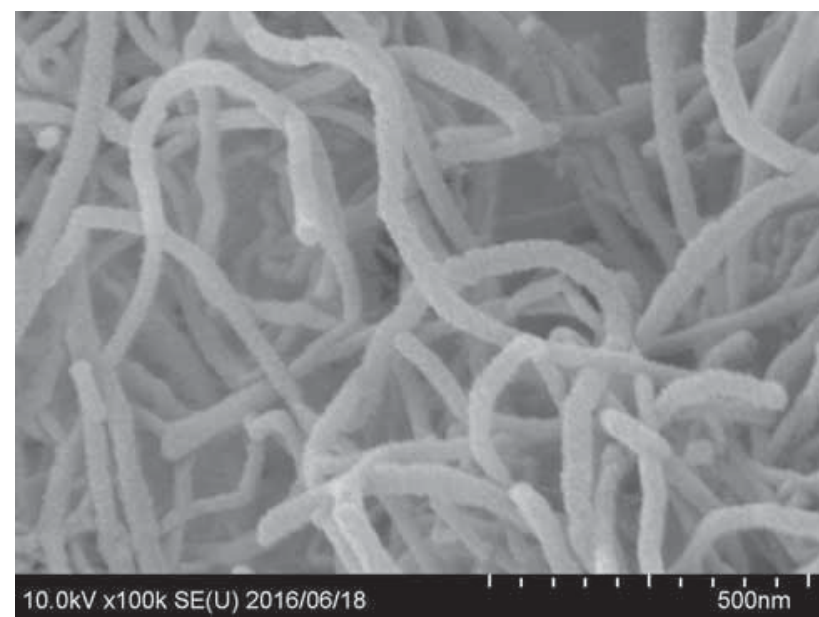

Figure 1. SEM image of CNTs.

$800^{\circ} \mathrm{C}$, using the catalyst $\mathrm{Fe} / \mathrm{Al}_{2} \mathrm{O}_{3}$. The tubes of material were uniform in the range $20-30 \mathrm{~nm}$ (see figure 1).

The resulting CNTs were suspended and sonicated for 15 min in concentrated $\mathrm{HNO}_{3}$ and $\mathrm{H}_{2} \mathrm{SO}_{4}$ with stirring, prior to the refluxing operation. The surface-modified CNTs were separated, washed by de-ionized water and dried at $80^{\circ} \mathrm{C}$ until unchanged weight.

\subsection{Methods}

2.2a Characterization of CNTs: The phases were identified using an X-ray diffractometer (XRD) (Model RINT2000/ PC (Rigaku, Tokyo, Japan)) with $\lambda_{\mathrm{CuK} \alpha}=0.15406 \mathrm{~nm}$, and a Fourier transform infrared (FT-IR) spectroscope (Model IRPrestige-21 (Shimadzu, Kyoto, Japan)). Raman spectrum was employed to realize the presence of defects on the surface of material using a Cary 5000 device (Netherlands). The particle morphology was studied using a field-emission scanning electron microscope (FE-SEM; Model S-4800 (Hitachi, Tokyo, Japan)), and a scanning transmission electron microscope (STEM) attached to the FE-SEM. The specific surface area was measured by nitrogen adsorption-desorption measurement at $77 \mathrm{~K}$ (Model BELSORP-mini, MicrotrackBEL, Osaka, Japan) and calculated on the basis of BrunauerEmmett-Teller (BET) theory.

2.2b Adsorption studies: All the working solutions of $\mathrm{Pb}^{2+}$ were further diluted from stock solution containing $1000 \mathrm{mg} \mathrm{l}^{-1} \mathrm{~Pb}^{2+}$ (Merck). The concentration of $\mathrm{Pb}^{2+}$ was determined by atomic absorption spectrometry (AAS). The adsorption capacity of $\mathrm{Pb}^{2+}$ is calculated as follows:

$$
q_{\mathrm{e}}=\frac{\left(C_{\mathrm{o}}-C_{\mathrm{e}}\right) V}{m},
$$

where $q_{\mathrm{e}}$ is $\mathrm{Pb}^{2+}$ adsorption capacity, $C_{\mathrm{o}}$ and $C_{\mathrm{e}}$ are concentrations of $\mathrm{Pb}^{2+}$ before and after adsorption, respectively, $m$ is the mass of surface-modified CNTs and $V$ is the volume of $\mathrm{Pb}^{2+}$ solution.

To determine the effect of $\mathrm{pH}$ on the removal of $\mathrm{Pb}^{2+}$ ions from aqueous solution, $10 \mathrm{mg}$ of surface-modified CNTs was dispersed in $50 \mathrm{ml}$ of $20 \mathrm{mg} \mathrm{l}^{-1} \mathrm{~Pb}^{2+}$ solution for $120 \mathrm{~min}$ and $\mathrm{pH}$ was varied from 2 to $6 . \mathrm{Pb}(\mathrm{OH})_{2}$ precipitation appeared when $\mathrm{pH}$ was more than 6 . The effect of adsorbent dosage on $\mathrm{Pb}^{2+}$ ion adsorption was also studied from 0.1 to $0.3 \mathrm{~g} \mathrm{l}^{-1}$.

For kinetic studies, the surface-modified CNTs were added to $250 \mathrm{ml}$ of $20 \mathrm{mg} \mathrm{l}^{-1} \mathrm{~Pb}^{2+}$ solution at $0.2 \mathrm{~g} \mathrm{l}^{-1}$ of CNTs dosage at $30^{\circ} \mathrm{C}$. After every $10 \mathrm{~min}, 10 \mathrm{ml}$ of the sample solution was taken out and the concentration of $\mathrm{Pb}^{2+}$ determined.

The maximum $\mathrm{Pb}^{2+}$ adsorption capacity $\left(q_{\mathrm{m}}\right)$ of the surface-modified CNTs was determined on the basis of isothermal data. The sample including $50 \mathrm{ml}$ of $\mathrm{Pb}^{2+}$ solutions was stirred at $30^{\circ} \mathrm{C}$ for $80 \mathrm{~min}$, using the solutions with the amounts ranging from 10 to $60 \mathrm{mg}^{-1}$. Here, the dosage of surface-modified CNTs was fixed at $0.2 \mathrm{~g}^{-1}$. The equilibrium amount of $\mathrm{Pb}^{2+}$ in the solution was determined after the adsorption.

The effect of temperature on $\mathrm{Pb}^{2+}$ removal reaction was surveyed from 10 to $50^{\circ} \mathrm{C}$. At each temperature, $250 \mathrm{ml}$ of $20 \mathrm{mg} \mathrm{l}^{-1} \mathrm{~Pb}^{2+}$ solution was stirred with $50 \mathrm{mg}$ of surfacemodified CNTs. After every $10 \mathrm{~min}, 10 \mathrm{ml}$ of the sample solution was taken out and the concentration of $\mathrm{Pb}^{2+}$ determined. Consequently, Gibbs free energy $\left(\Delta G^{\mathrm{o}}\right)$, enthalpy $\left(\Delta H^{\mathrm{o}}\right)$, entropy $\left(\Delta S^{\circ}\right)$ and activation energy $\left(E_{\mathrm{a}}\right)$ and activation enthalpy $\left(\Delta H^{*}\right)$ parameters of adsorption were determined.

\section{Results and discussion}

\subsection{Determination of suitable modification conditions of CNTs}

The surface modification of CNTs was carried out using a mixture of strong acids, i.e., $\mathrm{HNO}_{3}$ and $\mathrm{H}_{2} \mathrm{SO}_{4}$ (1:3 (volume)) [22-24]. Among these acids, $\mathrm{H}_{2} \mathrm{SO}_{4}$ was used to restrict the decomposition of $\mathrm{HNO}_{3}$ for the enhancement of oxidation ability. Firstly, the effects of oxidants concentration and modification temperature/time on the properties of CNTs were checked with the results shown in figure 2 . The surface of CNTs was oxidized by $100 \mathrm{ml}$ of mixture of acids; the concentrations of acids were varied from 3.25 to $16.25 \%$ for $\mathrm{HNO}_{3}$ and 14.70 to $73.50 \%$ for $\mathrm{H}_{2} \mathrm{SO}_{4}$ (figure $2 \mathrm{a}$ ). The non-surfacemodified CNTs exhibited low adsorption capacity of $\mathrm{Pb}^{2+}$ (approximately $10 \mathrm{mg} \mathrm{g}^{-1}$ ), much lower than that of surfacemodified CNTs. On the other hand, the higher the temperature and the longer the time, the higher the $\mathrm{Pb}^{2+}$ adsorption capacity. In the range of modification temperatures and times from 50 to $90^{\circ} \mathrm{C}$ and 5 to $8 \mathrm{~h}$, respectively, $\mathrm{Pb}^{2+}$ adsorption capacity attained $70 \mathrm{mg} \mathrm{g}^{-1}$ or higher values (figure $2 \mathrm{~b}$ and $\mathrm{c}$ ).

The effect of high modification temperatures and long times, as well as the increased concentration of oxidant $\left(\mathrm{HNO}_{3}-\mathrm{H}_{2} \mathrm{SO}_{4}\right.$ mixture), contributed to enhancing the $\mathrm{Pb}^{2+}$ adsorption capacity. The utilization of high concentration of 


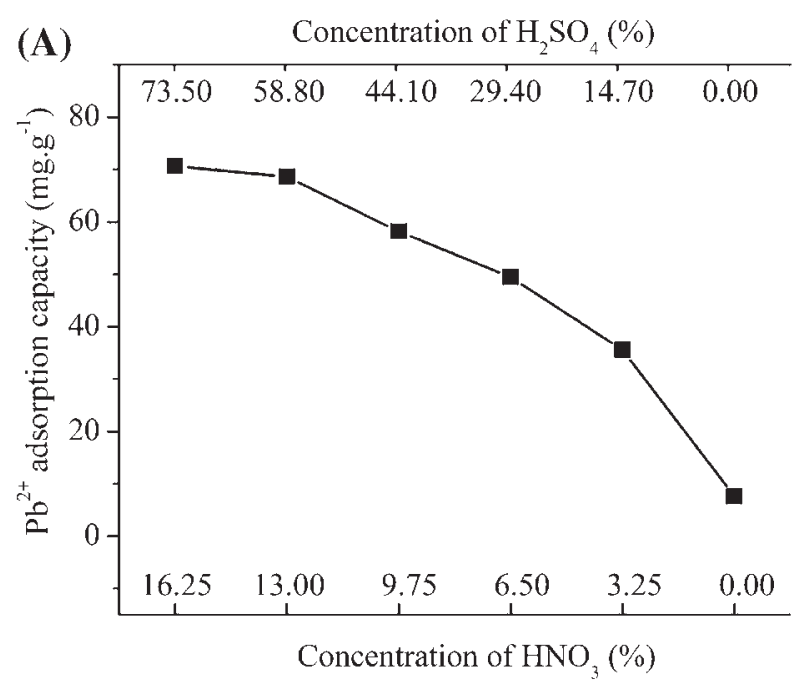

(B)

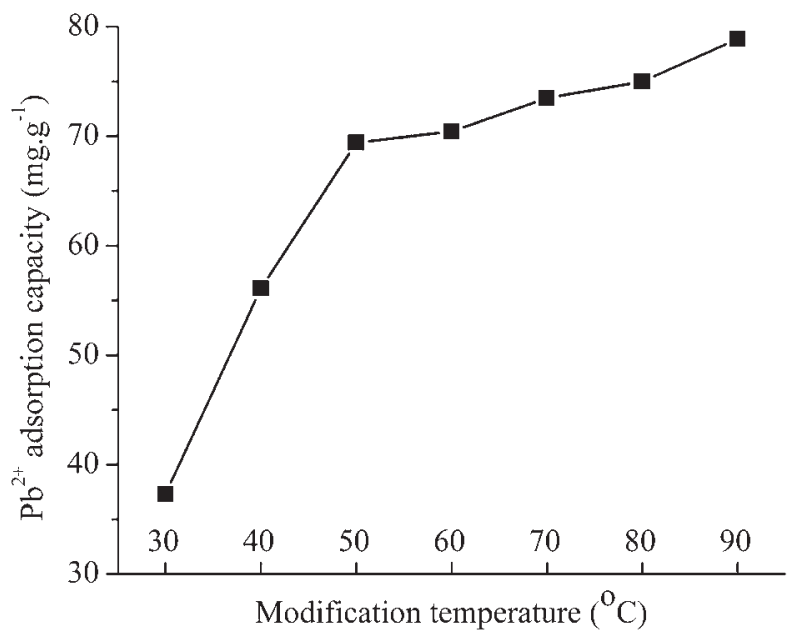

(C)

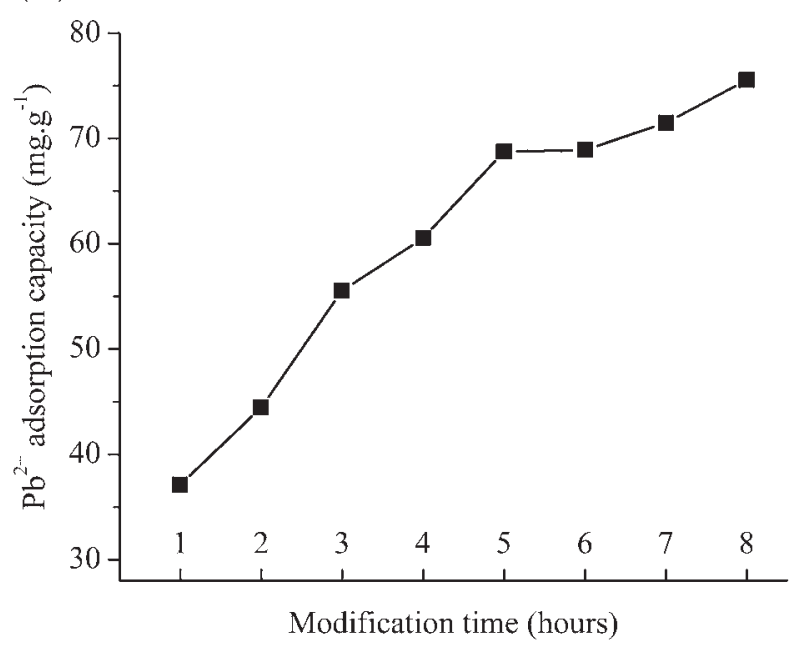

Figure 2. Effect of modification conditions on $\mathrm{Pb}^{2+}$ adsorption capacity: (A) oxidant concentrations; (B) modification temperature and $(\mathbf{C})$ modification time.

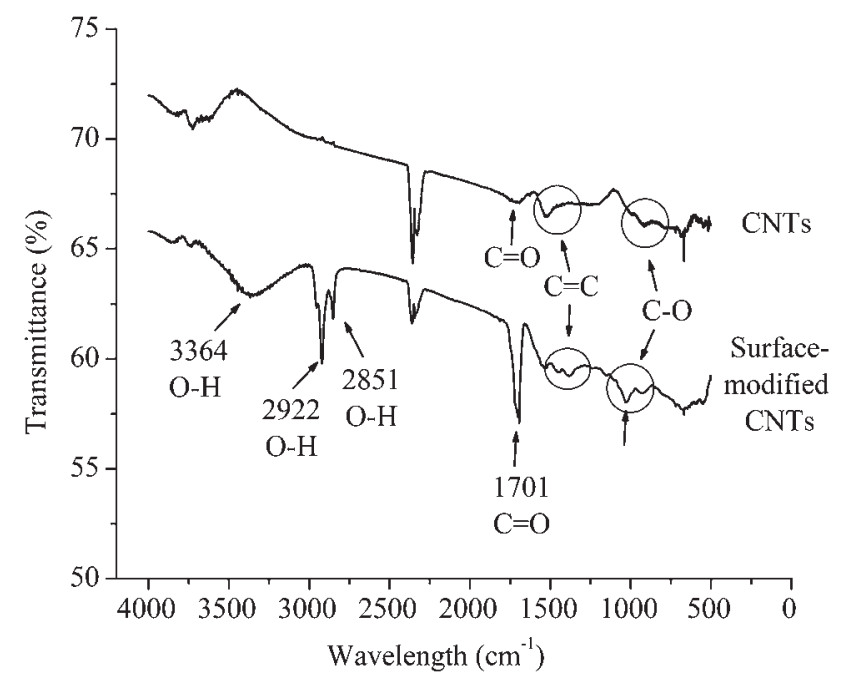

Figure 3. FT-IR studies performed on CNTs and modified CNTs samples.

acids, however, notably reduced the particle sizes, thereby making filtration of the modified CNTs difficult. This phenomenon may be explained in terms of the chemical degradation due to the attack of strong acids on the $\mathrm{C}-\mathrm{C}$ bonding within CNTs. We, therefore, carried out this surface modification operation at $50^{\circ} \mathrm{C}$ for $5 \mathrm{~h}$, using a mixture of $13 \%$ $\mathrm{HNO}_{3}$ and $58.80 \% \mathrm{H}_{2} \mathrm{SO}_{4}$ acids.

\subsection{Charaterization of modified CNTs}

The oxidation operation by strong acids is simple and effective for the formation of oxygen-containing functional groups on the CNTs. The formation of such funtional groups on the CNTs was checked by FT-IR spectroscopy, with the results shown in figure 3 .

Many peaks/bands of oxygen-containing groups were detected from the FT-IR spectrum. The band assigned to -OH groups of carboxylic acid, alcohol and water appeared at around 3364, 2922 and $2851 \mathrm{~cm}^{-1}$. Also, the $\mathrm{C}=\mathrm{O}$ groups, which proved the presence of $-\mathrm{COOH}$, appeared at around $1701 \mathrm{~cm}^{-1}$. Moosa et al [4], Li et al [25] and Wang et al [26] found similar characteristic peaks/bands for the oxidized CNTs. The weak peak at the wavenumber of around 1000 and $1400 \mathrm{~cm}^{-1}$ might be assigned to the $\mathrm{C}-\mathrm{O}$ and $\mathrm{C}=\mathrm{C}$ groups .

In order to identify the presence of defects on the surface of the modified CNTs caused by oxidation, Raman characterization was performed, and it is shown in figure 4 . The Raman D band (D-disorder) located at $1319 \mathrm{~cm}^{-1}$ is due to amorphous carbon and structural defects; graphite structures were proved by the $\mathrm{G}$ band ( $\mathrm{G}$-graphite) at $1567 \mathrm{~cm}^{-1}$. The $\mathrm{G}^{\prime}$ band at $2642 \mathrm{~cm}^{-1}$ is an overtone of the $\mathrm{D}$ band. The density of defects in the CNTs structure can be estimated by the ratio of integrated intensities of the $\mathrm{D}$ to $\mathrm{G}$ bands $\left(I_{\mathrm{D}} / I_{\mathrm{G}}\right)$ and $\mathrm{D}$ to $\mathrm{G}^{\prime}$ bands $\left(I_{\mathrm{D}} / I_{\mathrm{G}^{\prime}}\right)$. This means the larger the value of $I_{\mathrm{D}} / I_{\mathrm{G}}$ and $I_{\mathrm{D}} / I_{\mathrm{G}^{\prime}}$ ratios, the higher the defect density [27]. 


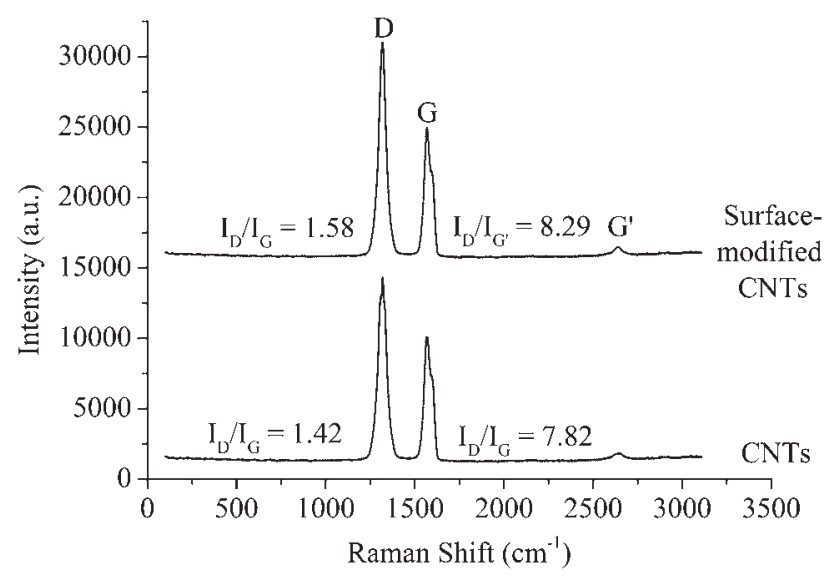

Figure 4. Raman studies performed on CNTs and surfacemodified CNTs samples.

Figure 4 shows that the values of $I_{\mathrm{D}} / I_{\mathrm{G}}$ and $I_{\mathrm{D}} / I_{\mathrm{G}^{\prime}}$ for the modified CNTs are both larger than those for non-modified CNTs. As a result of this, oxidation of surface of CNTs indeed bred defects in its structure.

EDX analysis of raw and surface-modified CNTs (figure 5) provided the evidence for the presence of carbon as the main component of both samples, in which the raw sample consisted of more percent (w/w) of carbon $(93.74 \%)$ than surface-modified one ( $88.93 \%)$. This might be because weight percent of oxygen increased strongly from $3.98 \%$ for initial CNTs to $10.30 \%$ for surface-modified CNTs, which demonstrated that functional groups containing oxygen appeared on the surface of CNTs. Additionally, small amounts of impurities, including $\mathrm{Fe}$ and $\mathrm{Al}$ derived from the catalysts, were detected by EDX. The decrease of weight percent of these elements after oxidation of CNTs proved the purification ability of the oxidation by acids because $\mathrm{Fe}$ and $\mathrm{Al}$ dissolved in acids.

Figure 6 shows the FE-SEM and STEM images of the surface-modified CNTs. The observation of FE-SEM images shows that the tube structure is still maintained after the oxidization by acid. Compared with the microstructure of raw CNTs (figure 1), however, most tubes seemed to be shorter in long-axis direction, reflecting the partial damage by oxidation of CNTs. On the other hand, rough surface of surface-modified CNTs observed through STEM images demonstrated the presence of defects on the surfaces of tubes, which was learnt also from Raman spectra.

The specific surface area of surface-modified CNTs measured by BET method was $159 \mathrm{~m}^{2} \mathrm{~g}^{-1}$, which is higher than that of raw CNTs $\left(134 \mathrm{~m}^{2} \mathrm{~g}^{-1}\right.$ ) (figure $7 \mathrm{a}$ and $\mathrm{b}$ ). The rupture of CNTs indicated the formation of defects, for example, increased amounts of pentagon and heptagon defects, thereby enhancing the surface area [28].

\section{$3.3 \mathrm{~Pb}^{2+}$ adsorption onto surface-modified CNTs}

3.3a Effect of $\mathrm{pH}$ : The point of zero charge (PZC) is a concept related to the characteristics of adsorption, i.e., the
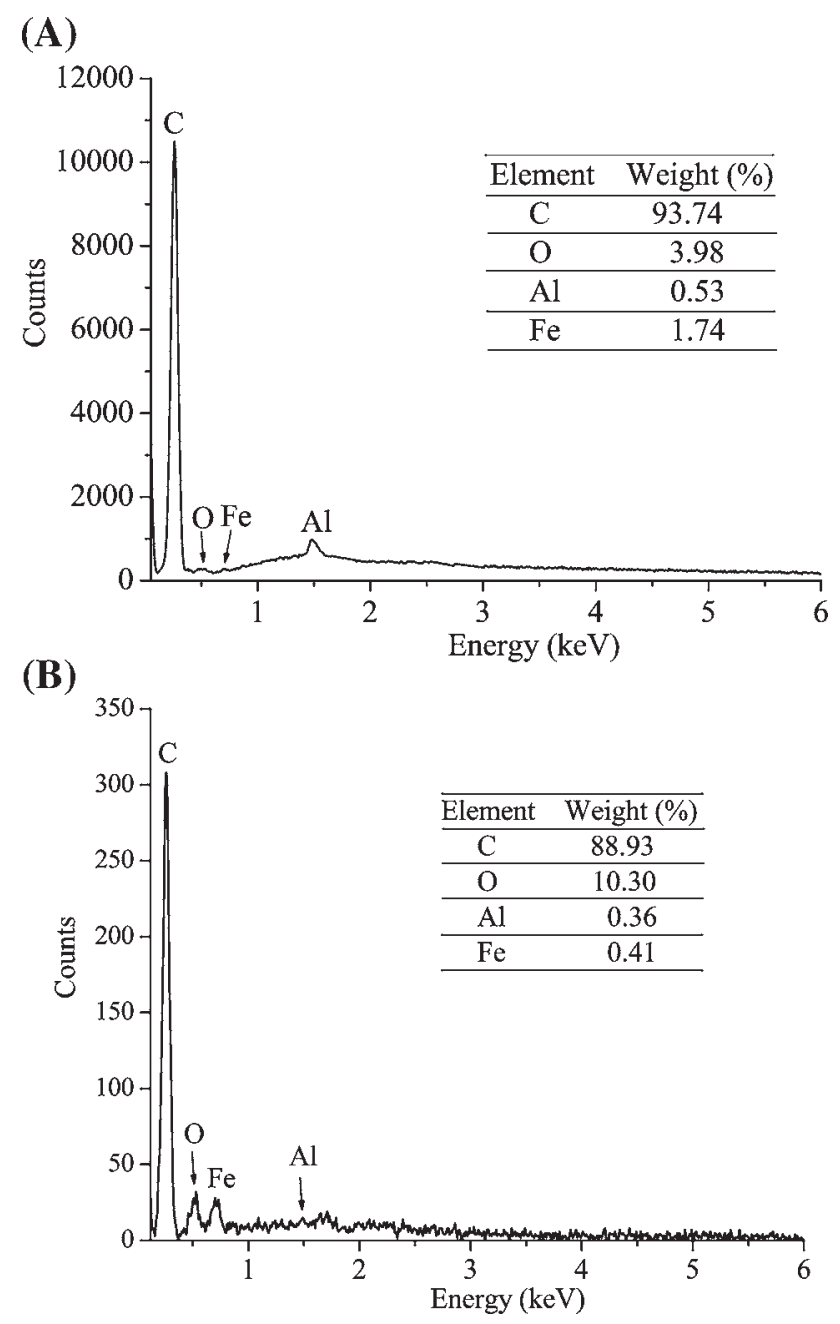

Figure 5. EDX analyses of CNTs (A) and surface-modified CNTs (B) samples.

electrical charge density on the surface is zero. When the $\mathrm{pH}$ is higher than PZC value, the basic solution donates more hydroxide groups $\left(\mathrm{OH}^{-}\right)$than protons $\left(\mathrm{H}^{+}\right)$, and the surfaces of CNTs are negatively charged and favourable for attracting cations. Conversely, below the PZC, the positively charged surface is not advantageous to the adsorption of cations. The relationship between $\mathrm{pH}$ and $\mathrm{Pb}^{2+}$ adsorption capacity is shown in figure 8.

The value of PZC of surface-modified CNTs reported previously was about 5 [29]. The experimental data showed that the enhancement of $\mathrm{pH}$ from 2 to 5 reduced the positive charge on the surface of CNTs and increased $\mathrm{Pb}^{2+}$ adsorption capacity from 2.65 to $55.55 \mathrm{mg} \mathrm{g}^{-1}$. At $\mathrm{pH} 6$, the surface-modified CNTs exhibited the highest $\mathrm{Pb}^{2+}$ adsorption capacity $\left(70.60 \mathrm{mg} \mathrm{g}^{-1}\right.$ ) or suitable $\mathrm{pH}$ for $\mathrm{Pb}^{2+}$ adsorption. The present results have been supported by Tehrani et al [30].

3.3b Effect of surface-modified CNTs (adsorbent) dosage: Changes in $\mathrm{Pb}^{2+}$ adsorption capacity are shown in figure 9, 

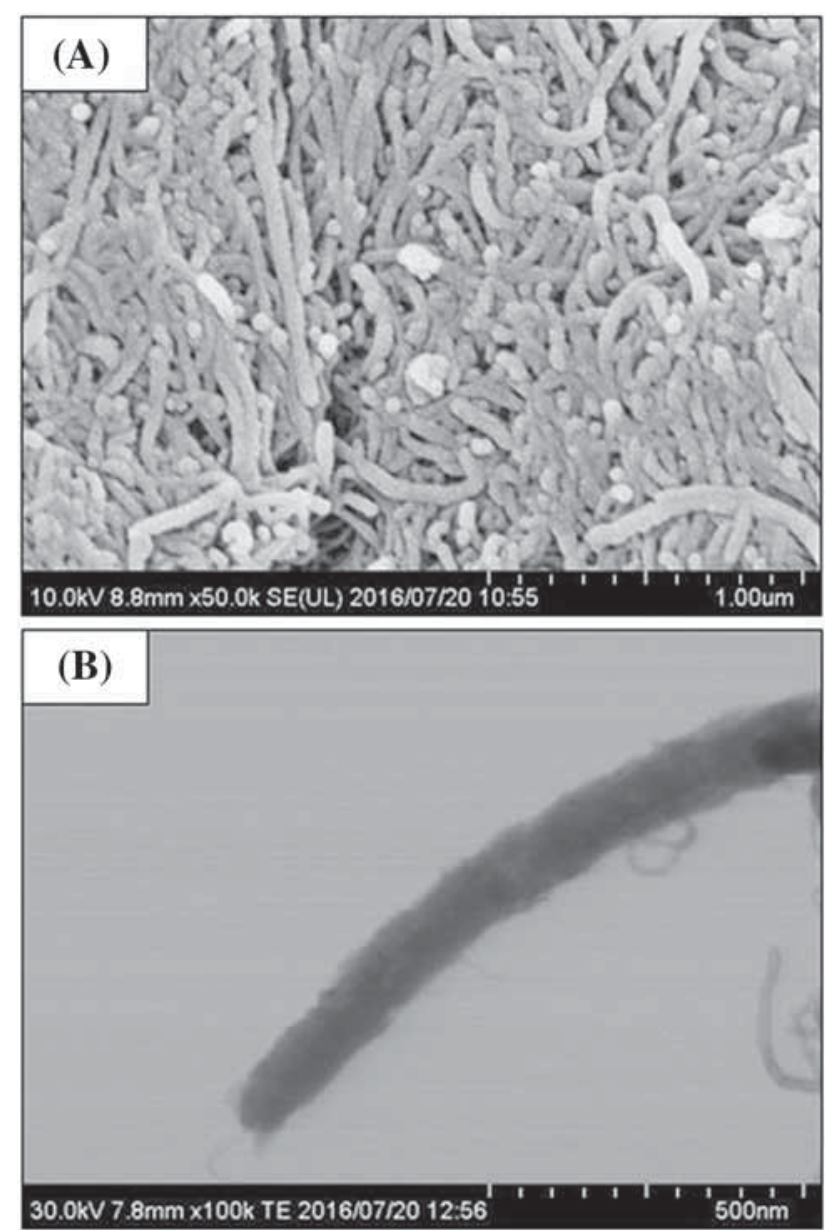

Figure 6. FE-SEM (A) and STEM (B) images of surface-modified CNTs sample.

as a function of CNTs dosage amount. On increasing initial $\mathrm{Pb}^{2+}$ concentration to $20 \mathrm{mg} \mathrm{l}^{-1}$, a strong uptrend of $\mathrm{Pb}^{2+}$ adsorption capacity was observed from 33.60 to $68.75 \mathrm{mg} \mathrm{g}^{-1}$ when the amount of CNTs dosage increased from 0.1 to $0.2 \mathrm{gl}^{-1}$. Subsequently, $\mathrm{Pb}^{2+}$ adsorption capacity slightly varied around the value of $68 \mathrm{mg} \mathrm{g}^{-1}$. Thus the suitable amount of surface-modified CNTs for $\mathrm{Pb}^{2+}$ removal was determined as $0.2 \mathrm{gl}^{-1}$.

3.3c Effect of $\mathrm{Cu}^{2+}$ ions: United States Environmental Protection Agency (EPA) put forward some federal regulations for drinking water, and among them, Lead and Copper Rule is one of these regulations, which limits the concentration of lead and copper allowed in public drinking water at the consumer's tap [31,32]. In the present study, the effect of the presence of $\mathrm{Cu}^{2+}$ in solution on $\mathrm{Pb}^{2+}$ adsorption capacity of adsorbent was investigated. The initial $\mathrm{Pb}^{2+}$ was 10,20 and $30 \mathrm{mg} \mathrm{l}^{-1}$ and the added $\mathrm{Cu}^{2+}$ concentration varied from 0 to $30 \mathrm{mg} \mathrm{l}^{-1}$. The effect of added $\mathrm{Cu}^{2+}$ concentration on the $\mathrm{Pb}^{2+}$ adsorption capacity is presented in figure 10 . The results showed that the higher the concentration of $\mathrm{Cu}^{2+}$ in
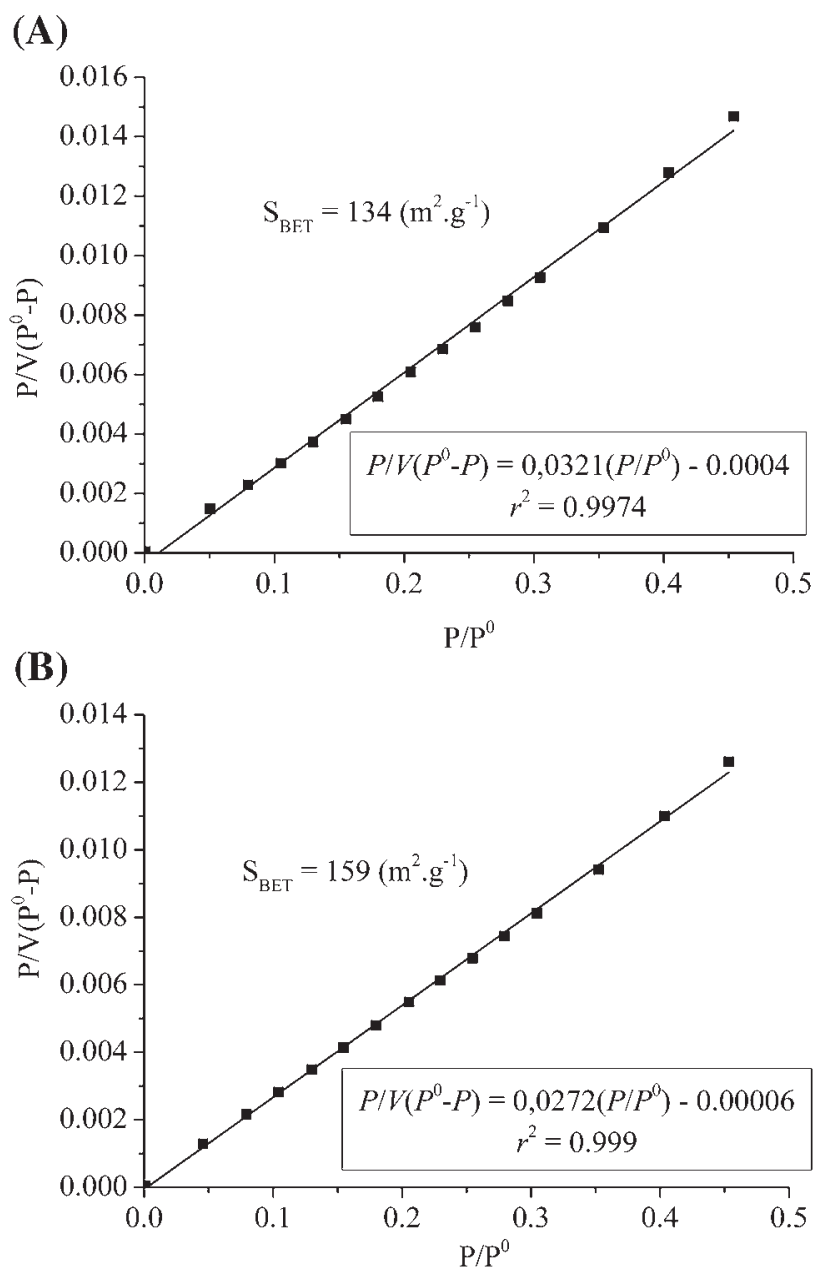

Figure 7. BET analyses of CNTs (A) and surface-modified CNTs (B) samples.

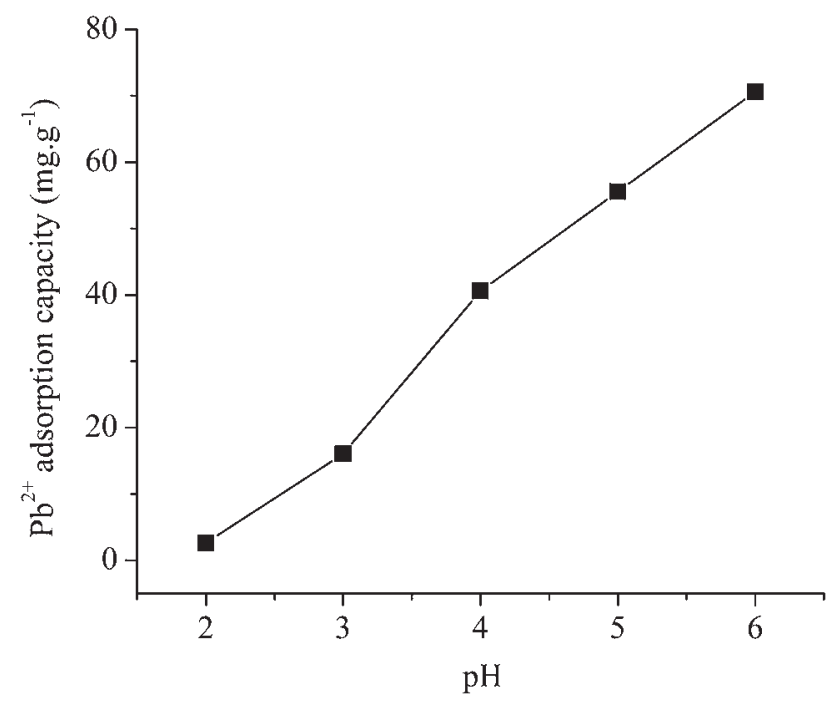

Figure 8. Effect of $\mathrm{pH}$ on $\mathrm{Pb}^{2+}$ adsorption capacity. 


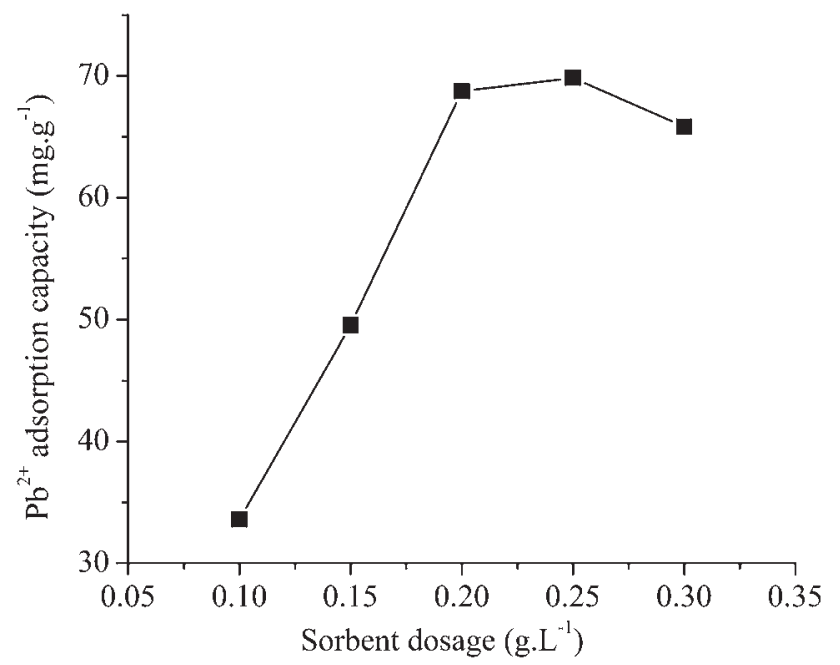

Figure 9. Effect of sorbent dosage on $\mathrm{Pb}^{2+}$ adsorption capacity.

solution, the lower the $\mathrm{Pb}^{2+}$ adsorption capacity of modified CNTs. This can be explained based on the fact that affinity of $\mathrm{Cu}^{2+}$ ions towards surface of adsorbent hindered the contact between $\mathrm{Pb}^{2+}$ ions and adsorption centres existing on its surface. Therefore, $\mathrm{Pb}^{2+}$ adsorption of adsorbent was partly impeded by the presence of $\mathrm{Cu}^{2+}$ ions.

Figure $10 \mathrm{~b}$ shows the increase of the total adsorption capacity of modified CNTs when $\mathrm{Cu}^{2+}$ concentration is lower than $15 \mathrm{mg}^{-1}$ and after this, there is no remarkable change of $\mathrm{Pb}^{2+}$ adsorption capacity when $\mathrm{Cu}^{2+}$ concentration increases from 15 to $30 \mathrm{mg}^{-1}$. This demonstrated that the addition of other heavy metals cations seemed not to change total adsorption capacity of modified CNTs. In other words, $\mathrm{Pb}^{2+}$ selectivity of modified CNTs was not high.

3.3d Adsorption kinetics: Figure 11 shows the changes in $\mathrm{Pb}^{2+}$ adsorption capacity of surface-modified CNTs with time at different temperatures. $\mathrm{Pb}^{2+}$ adsorption capacity increased with time and showed a maximum after around $80 \mathrm{~min}$ at all surveyed temperatures; with further increase in time, however, the variation was not remarkable. This fact indicates that $\mathrm{Pb}^{2+}$ adsorption of surface-modified CNTs reached equilibrium state after $80 \mathrm{~min}$.

These data were applied to a pseudo-first-order rate model (equation (2)) or pseudo-second-order rate model (equation (3)) $[6,33]$. The pseudo-first-order and pseudo-second-order kinetic equations are given, respectively, as follows:

$$
\begin{aligned}
& \ln \left(q_{\mathrm{e}}-q_{\mathrm{t}}\right)=\ln q_{\mathrm{e}}-k_{1} t \\
& \frac{t}{q_{\mathrm{t}}}=\frac{1}{k_{2} q_{\mathrm{e}}^{2}}+\frac{t}{q_{\mathrm{e}}}
\end{aligned}
$$

where $q_{\mathrm{e}}$ and $q_{t}$ are $\mathrm{Pb}^{2+}$ adsorption capacities at equilibrium and any time, respectively; $k_{1}$ and $k_{2}$ are pseudo-first-order and pseudo-second-order rate constants, respectively.
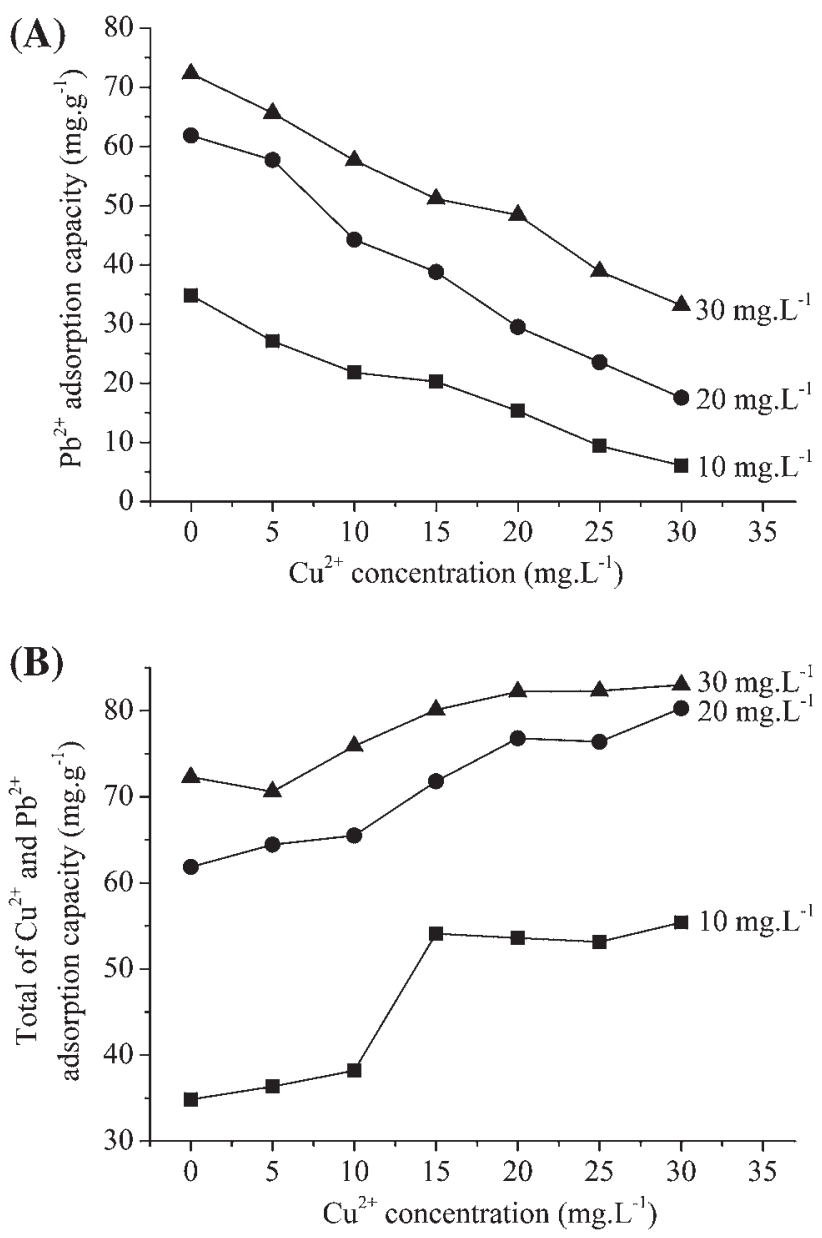

Figure 10. Effect of $\mathrm{Cu}^{2+}$ ions to $(\mathbf{A}) \mathrm{Pb}^{2+}$ adsorption capacity and $(\mathbf{B})$ total of $\mathrm{Pb}^{2+}$ and $\mathrm{Cu}^{2+}$ adsorption capacity.

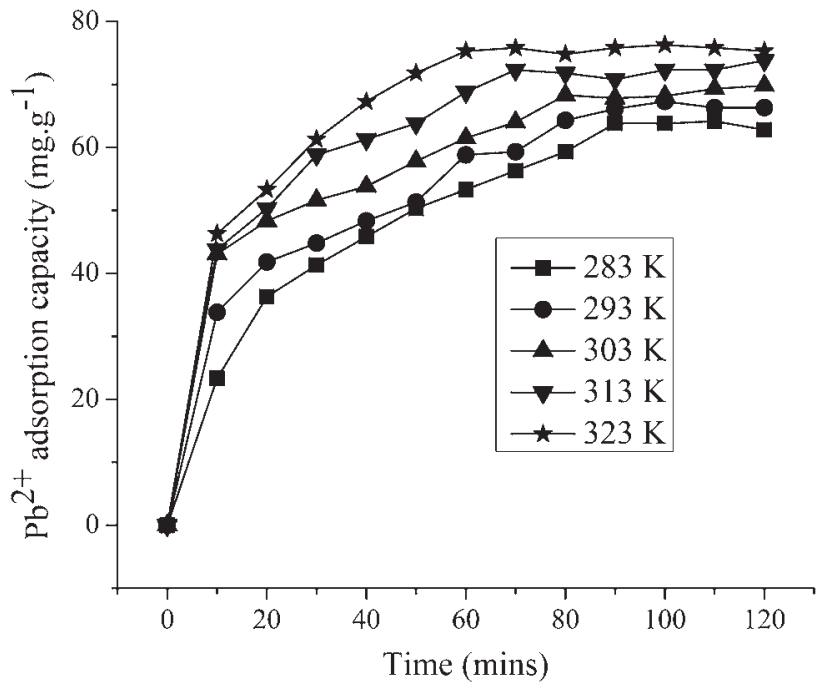

Figure 11. $\mathrm{Pb}^{2+}$ adsorption capacity of surface-modified CNTs for different times at different temperatures. 
Table 1. Parameters of the pseudo-first-order and pseudo-second-order kinetic equations at surveyed temperatures.

\begin{tabular}{|c|c|c|c|c|c|}
\hline \multirow[b]{2}{*}{ Temperature $\left({ }^{\circ} \mathrm{C}\right)$} & \multicolumn{2}{|c|}{ Pseudo-first-order kinetic equation } & \multicolumn{2}{|c|}{ Pseudo-second-order kinetic equation } & \multirow{2}{*}{$\begin{array}{c}q_{\mathrm{e}} \text { experimental } \\
\left(\mathrm{mg} \mathrm{g}^{-1}\right)\end{array}$} \\
\hline & $q_{\mathrm{e}}\left(\mathrm{mg} \mathrm{g}^{-1}\right)$ & $r^{2}$ & $q_{\mathrm{e}}\left(\mathrm{mg} \mathrm{g}^{-1}\right)$ & $r^{2}$ & \\
\hline 10 & 48.35 & 0.976 & 78.13 & 0.994 & 63.8 \\
\hline 20 & 59.13 & 0.866 & 78.13 & 0.989 & 66.1 \\
\hline 30 & 37.52 & 0.946 & 77.52 & 0.994 & 68.3 \\
\hline 40 & 45.91 & 0.945 & 80.00 & 0.998 & 72.3 \\
\hline 50 & 57.86 & 0.963 & 81.96 & 0.998 & 75.3 \\
\hline
\end{tabular}

As shown in table 1, the correlation coefficients of the pseudo-second-order kinetic equation at all surveyed temperatures were all higher than those of pseudo-first-order kinetic equation. On the other hand, with the increase of temperature, the model values of equilibrium adsorption capacity $\left(q_{\mathrm{e}}\right)$ calculated from pseudo-second-order kinetic equation were more consistent with experimental values than those calculated from pseudo-first-order kinetic equation. This confirmed that the pseudo-second-order kinetic model described the adsorption of $\mathrm{Pb}^{2+}$ onto the modified CNTs well. In other words, $\mathrm{Pb}^{2+}$ adsorption onto surface-modified CNTs at low initial concentration may be controlled by chemisorption process [34].

The activation energy refers to the minimum amount of energy that must be overcome for adsorption. The activation energy, $E_{\mathrm{a}}$, was determined by Arrhenius equation

$$
k_{T}=A e^{-E_{\mathrm{a}} / R T}
$$

Taking the natural logarithm on both sides of equation (4), one obtains

$$
\ln k_{T}=\ln A-\frac{E_{\mathrm{a}}}{R T}
$$

where $A$ is the pre-exponential factor; $R$ is the universal gas constant, which is $8.314 \mathrm{~J} \mathrm{~mol}^{-1} \mathrm{~K}^{-1}$; $T$ is absolute temperature in Kelvin $(\mathrm{K})$.

Figure 12 illustrates the linear plot of $\ln k_{T} v s .1 / T . E_{\mathrm{a}}$ can be obtained from the slope $\left(-E_{\mathrm{a}} / R\right)$. The obtained $E_{\mathrm{a}}$ (using the Arrhenius equation) was $21.08 \mathrm{~kJ} \mathrm{~mol}^{-1}$. Low activation energy (below $42 \mathrm{~kJ} \mathrm{~mol}^{-1}$ ) implies diffusion-controlled process because the temperature dependence of pore diffusivity is relatively weak and the diffusion process refers to the movement of the solute to an external surface and not diffusivity of material along microscope surfaces in a particle.

Thermodynamic parameters of activation can inform whether or not the adsorption process follows an activated complex prior to the final adsorption. Thermodynamic parameters of activation, including the enthalpy $\left(\Delta H^{\#}\right)$, entropy $\left(\Delta S^{\#}\right)$ and Gibbs free energy $\left(\Delta G^{\#}\right)$ of activation for $\mathrm{Pb}^{2+}$ adsorption kinetics, were obtained by applying the Eyring

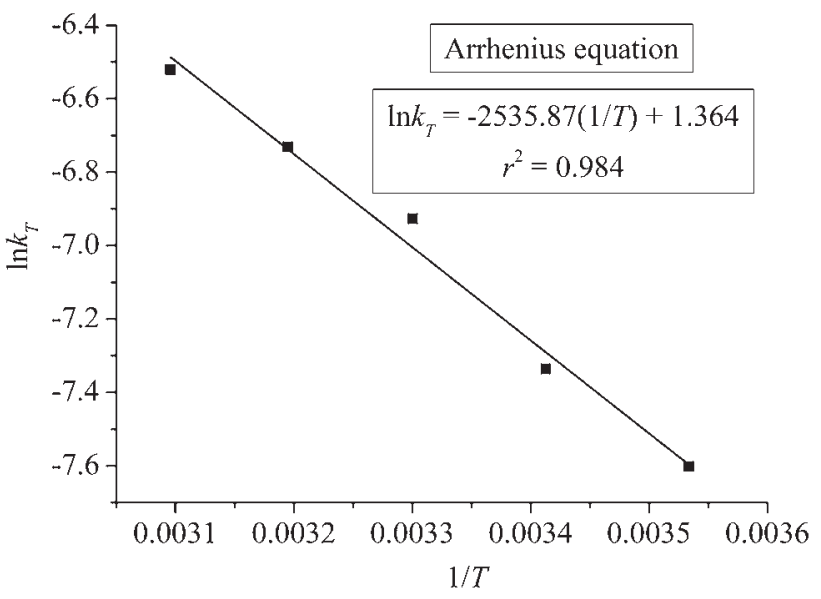

Figure 12. Arrhenius plot studied on $\mathrm{Pb}^{2+}$ adsorption onto surface-modified CNTs.

equation. The linear form of Eyring equation is expressed as follows:

$$
\ln \frac{k_{T}}{T}=-\frac{\Delta H^{\#}}{R T}+\ln \frac{k_{\mathrm{B}}}{h}+\frac{\Delta S^{\#}}{R},
$$

where $k_{T}$ is the rate constant, equal to the rate constant in the pseudo-second-order model, $K B\left(1.3807 \cdot 10^{-23} \mathrm{~J} \mathrm{~K}^{-1}\right)$ is the Boltzmann constant and $h(6.621 \mathrm{~J} \mathrm{~s})$ is the Planck constant.

Using the linear plot of $\ln (k / T) v s .1 / T$, the $\Delta S^{\#}$ and $\Delta H^{\#}$ were obtained from the slope $\left(-\Delta H^{\#} / T\right)$ and $y$-intercept $\left[\ln \left(k_{\mathrm{B}} / h+\left(\Delta S^{\#} / R\right)\right]\right.$. The linear plot of $\ln (k / T) v s .1 / T$ is presented in figure 13. Activation parameters for $\mathrm{Pb}^{2+}$ adsorption are shown in table 2.

Positive value of $\Delta S^{\#}\left(466.27 \mathrm{~J} \mathrm{~mol}^{-1} \mathrm{~K}^{-1}\right)$ suggests a possibility of an associative chemisorption through the formation of an activated complex between $\mathrm{Pb}^{2+}$ molecule and adsorbent. Also, positive value of $\Delta S^{\#}$ normally reflects that no significant change occurs in the internal structure of the adsorbent during the adsorption process $[35,36]$. The values for $\Delta H^{\#}\left(18.6 \mathrm{~kJ} \mathrm{~mol}^{-1}\right)$ suggest that the reactions are endothermic. The large, negative $\Delta G^{\#}$ implies that in these reactions, activated complex occurs spontaneously. 


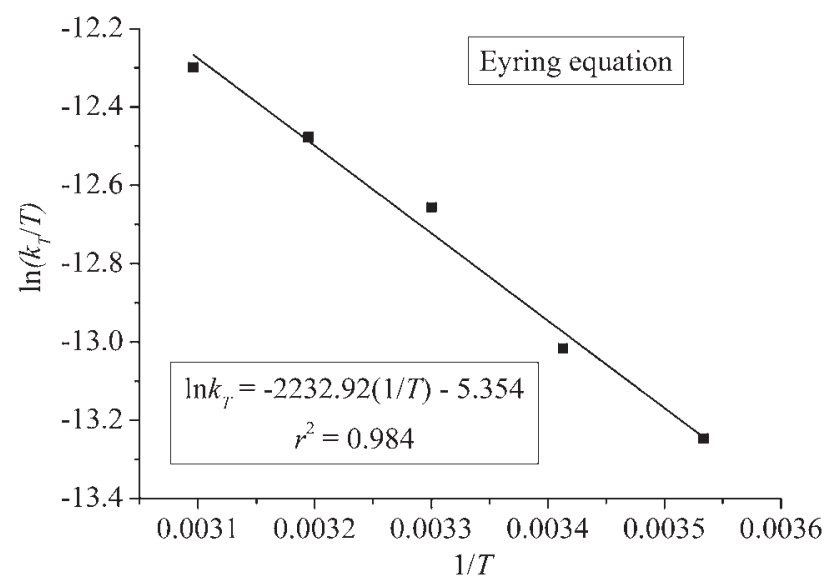

Figure 13. Eyring plot studied on $\mathrm{Pb}^{2+}$ adsorption onto surfacemodified CNTs.

This result emphasizes two important points: (i) the adsorption of $\mathrm{Pb}^{2+}$ onto modified CNTs takes place mainly on the outside surface of CNTs and the structure of CNTs is not changed because $\mathrm{Pb}^{2+}$ does not diffuse inside the tubes; (ii) the reaction between $\mathrm{Pb}^{2+}$ ions in solution and functional groups on the surface of CNTs such as $-\mathrm{COOH}$ and $-\mathrm{OH}$ might be ion exchange reaction, which means each $\mathrm{Pb}^{2+}$ ion in solution would bond with two $\mathrm{O}$ atoms of two groups of $-\mathrm{COOH}$ or one group of $-\mathrm{COOH}$ and one group of $-\mathrm{OH}$ and replace two $\mathrm{H}^{+}$ions [32]. The ion exchange mechanism can be supported by the change of $\mathrm{pH}$ and electrical conductivity values of solution before and after adsorption at $30^{\circ} \mathrm{C}$, as shown in figure 14.

Clearly, it is found that in case of the solution containing high amount of $\mathrm{H}^{+}$ions, the electrical conductivity of solution will be high, because the ionic mobility of $\mathrm{H}^{+}$is larger than that of $\mathrm{Pb}^{2+}$. The results indicate that the solutions after the adsorption at initial concentrations from 20 to $60 \mathrm{mg} \mathrm{l}^{-1}$ exhibit lower values of $\mathrm{pH}$ and higher values of electrical conductivity than the case before the adsorption, which means that the solution after the adsorption contains more amount of $\mathrm{H}^{+}$ions than the case before the adsorption. This mechanism is illustrated by schema 1 .

3.3e Adsorption isotherm: Langmuir and Freundlich isotherm models $[6,28,33]$ are used in order to evaluate the
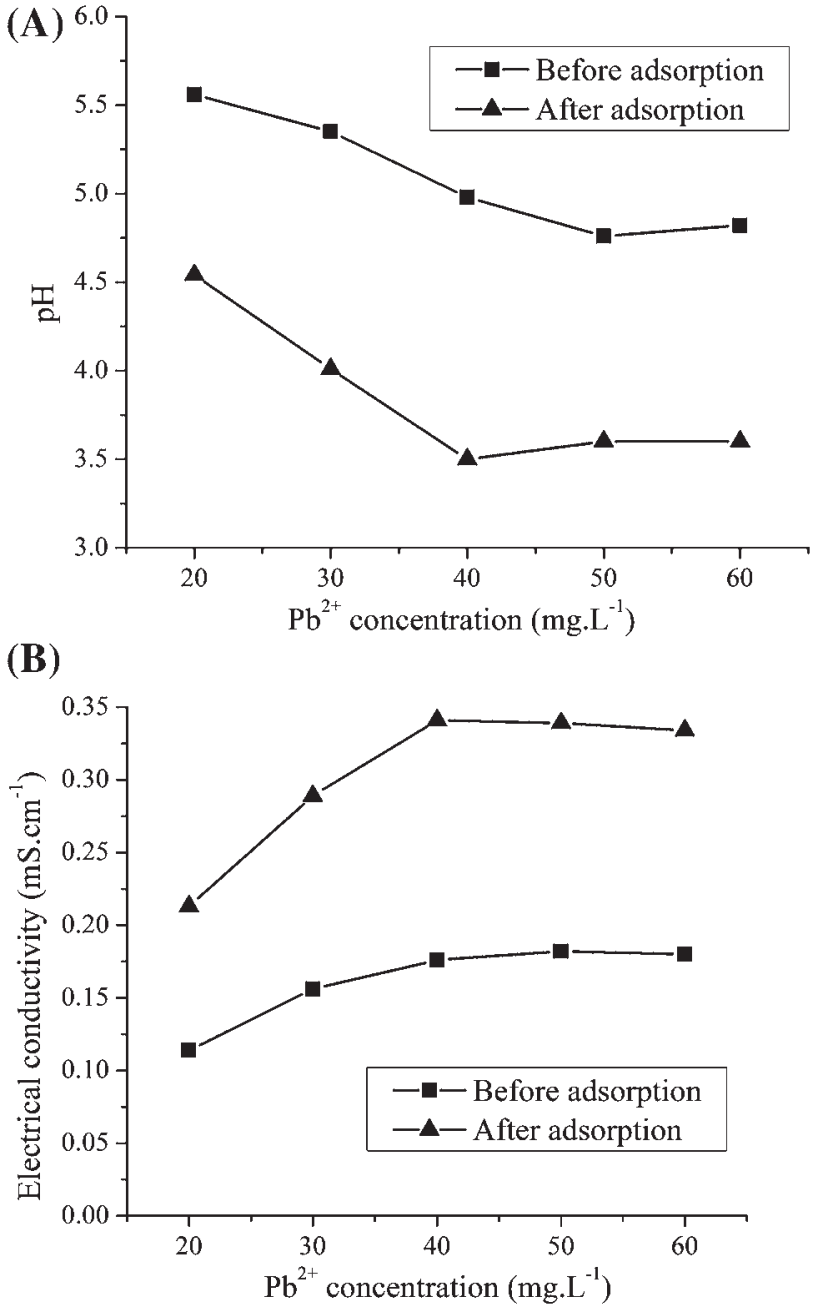

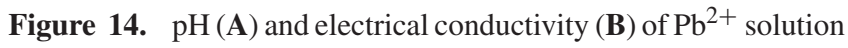
before and after adsorption.

adsorption as follows:

$$
\begin{aligned}
\frac{C_{\mathrm{e}}}{q_{\mathrm{e}}} & =\frac{C_{\mathrm{e}}}{q_{\mathrm{m}}}+\frac{1}{K_{\mathrm{L}} q_{\mathrm{m}}} \\
\ln q_{\mathrm{e}} & =\ln K_{\mathrm{F}}+n \ln C_{\mathrm{e}}
\end{aligned}
$$

where $C_{\mathrm{e}}$ is the equilibrium concentration of $\mathrm{Pb}^{2+}$ in the solution after adsorption, $q_{\mathrm{e}}$ is $\mathrm{Pb}^{2+}$ adsorption capacity of modified CNTs that is calculated by equation (1), $q_{\mathrm{m}}$ is

Table 2. Activation parameters for $\mathrm{Pb}^{2+}$ adsorption onto surface-modified CNTs.

\begin{tabular}{lccc}
\hline Temperature $(\mathrm{K})$ & $\Delta H^{\#}\left(\mathrm{~kJ} \mathrm{~mol}^{-1}\right)$ & $\Delta S^{\#}\left(\mathrm{~J} \mathrm{~mol}^{-1} \mathrm{~K}^{-1}\right)$ & $\Delta G^{\#}\left(\mathrm{~kJ} \mathrm{~mol}^{-1}\right)$ \\
\hline 283 & 18.56 & 466.27 & -113.39 \\
293 & & & -118.05 \\
303 & & -122.72 \\
313 & & -127.38 \\
323 & & -132.04 \\
\hline
\end{tabular}



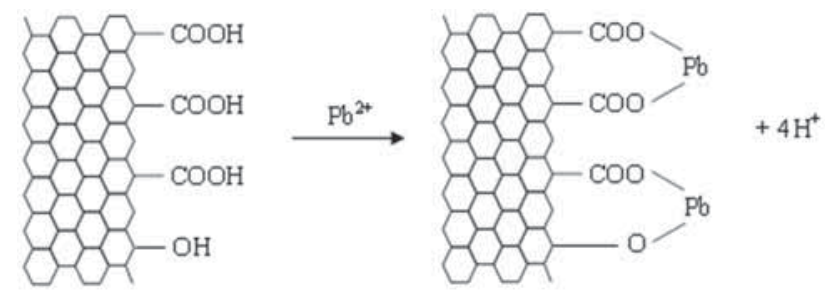

Scheme 1. Ion exchange mechanism of $\mathrm{Pb}^{2+}$ adsorption onto modified CNTs.

maximum $\mathrm{Pb}^{2+}$ adsoprtion capacity and $K_{\mathrm{L}}$ is the Langmuir constant, which is related to the strength of adsorption. An essential characteristic of Langmuir isotherm can be expressed by a dimensionless constant called equilibrium parameter:

$$
R_{\mathrm{L}}=\frac{1}{1+K_{\mathrm{L}} C_{\mathrm{o}}},
$$

where $C_{\mathrm{o}}$ is the highest initial concentration of $\mathrm{Pb}^{2+}$ and the value of $R_{\mathrm{L}}$ indicates the type of the isotherm; $K_{\mathrm{F}}$ and $n$ are Fruendlich constants [33].

Figure 15 illustrates the linear correlation between $q_{\mathrm{e}}$ and $C_{\mathrm{e}}$ corresponding to Langmuir and Freundlich isotherm models. The correlation coefficient for the Langmuir model $\left(r^{2}=0.996\right)$ was greater than that of the Freundlich model $\left(r^{2}=0.682\right)$. This fact indicates that the adsorption is in the monolayer form, i.e., experimental data are in agreement with the Langmuir model.

The equilibrium parameter $\left(R_{\mathrm{L}}\right)$ value of 0.06 characterizing dimensionless constant calculated from Langmuir model approximated to zero and was in the range $0-1$. The maximum $\mathrm{Pb}^{2+}$ adsorption capacity $\left(q_{\mathrm{m}}\right)$ was $100 \mathrm{mg} \mathrm{g}^{-1}$.

These results indicate that $\mathrm{Pb}^{2+}$ adsorption onto modified CNTs takes place favourably and irreversibly, and this sorbent has good adsorption capacity. In comparison with the adsorbents of many studies listed in table 3 , maximum $\mathrm{Pb}^{2+}$ adsorption capacity of our material was much higher than in the previous research. This proved that the simultaneous use of $\mathrm{HNO}_{3}$ and $\mathrm{H}_{2} \mathrm{SO}_{4}$ enhances the efficiency of surface modification. Thereby, the number of oxygen-containing groups on the surface of CNTs is increased; more $\mathrm{Pb}^{2+}$ ions can approach the surface of CNTs and replace $\mathrm{H}^{+}$ions of these groups.

3.3f Thermodynamic studies: The equilibrium constant of adsorption $\left(K_{\mathrm{c}}\right)$ is calculated by the following equation [26]:

$$
K_{\mathrm{c}}=\frac{C_{\mathrm{ae}}}{C_{\mathrm{e}}}=\frac{q_{\mathrm{e}}}{C_{\mathrm{e}}}
$$

where $C_{\mathrm{ae}}$ and $C_{\mathrm{e}}$ are equilibrium $\mathrm{Pb}^{2+}$ concentration on the adsorbent and in solution, respectively.
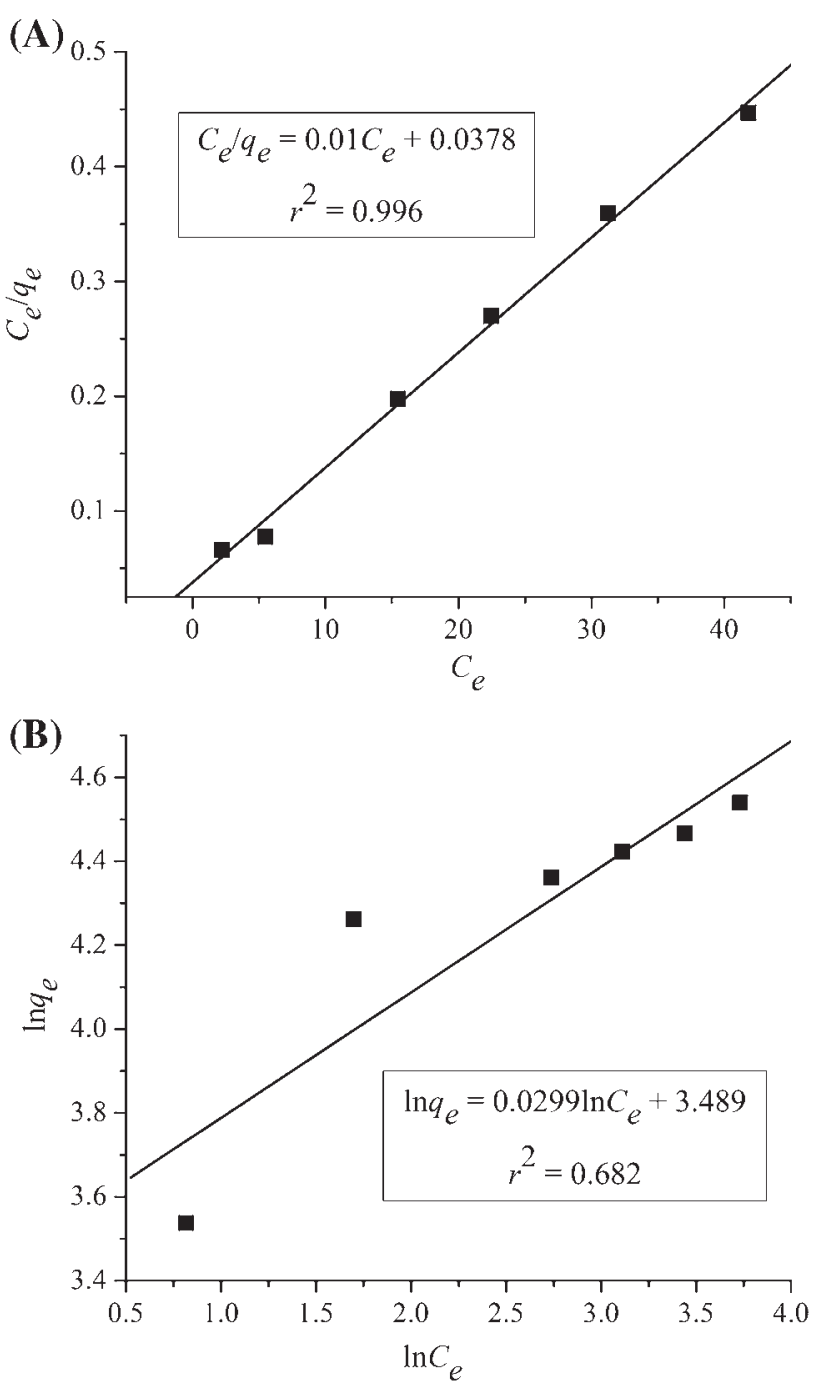

Figure 15. Langmuir (A) and Freundlich (B) isotherm models for $\mathrm{Pb}^{2+}$ adsorption onto modified CNTs.

Further, Gibbs free energy $\left(\Delta G^{\circ}\right)$ parameter of adsorption was determined by equation (11), whereas enthalpy $\left(\Delta H^{0}\right)$ and entropy $\left(\Delta S^{\circ}\right)$ parameters were calculated on the basis of Van't Hoff equation (equation (12)):

$$
\begin{aligned}
\Delta G^{\mathrm{o}} & =-R T \ln K_{\mathrm{c}} \\
\ln K_{\mathrm{c}} & =-\frac{\Delta G^{\mathrm{o}}}{R T}=\frac{\Delta S^{\mathrm{o}}}{R}-\frac{\Delta H^{\mathrm{o}}}{R T}
\end{aligned}
$$

Thermodynamic nature of $\mathrm{Pb}^{2+}$ adsorption onto surfacemodified CNTs was examined through thermodynamic parameters $\Delta G^{\mathrm{o}}, \Delta H^{\mathrm{o}}$ and $\Delta S^{\mathrm{o}}$ calculated from equations (10)(12), as shown in table 4.

The experimental data show that $\mathrm{Pb}^{2+}$ adsorption capacity increased with temperature. The positive value of standard calorific effect $\left(\Delta H^{\mathrm{o}}=11.56 \mathrm{~kJ} \mathrm{~mol}^{-1}\right)$ confirmed the endothermic nature of adsorption. Gibbs free energy variation 
Table 3. Isotherm parameters calculated from Langmuir model of $\mathrm{Pb}^{2+}$ adsorption onto many kinds of surface-modified CNTs.

\begin{tabular}{|c|c|c|c|}
\hline Sorbents & $q_{\mathrm{m}}\left(\mathrm{mg} \mathrm{g}^{-1}\right)$ & $r^{2}$ & References \\
\hline CNTs refluxed in $\mathrm{HNO}_{3}$ and $\mathrm{H}_{2} \mathrm{SO}_{4}$ & 100.00 & 0.996 & Present study \\
\hline CNTs refluxed in $\mathrm{HNO}_{3}$ at $120^{\circ} \mathrm{C}$ for $48 \mathrm{~h}$ & 6.6 & 0.973 & {$[18]$} \\
\hline CNTs refluxed in $\mathrm{HNO}_{3}$ at $140^{\circ} \mathrm{C}$ for $5 \mathrm{~h}$ & 17.44 & 0.905 & [19] \\
\hline CNTs & 15.34 & 0.988 & {$[20]$} \\
\hline CNTs ultrasonically stirred for $24 \mathrm{~h}$ in $\mathrm{HNO}_{3}$ & $2.06-11.70$ & 0.955 & {$[21]$} \\
\hline CNTs dispersed into Tris(2-aminoethyl)amine & 71 & 0.986 & {$[30]$} \\
\hline MWCNTs & 61.35 & 0.998 & {$[34]$} \\
\hline MWCNTs oxidized by $\mathrm{NaClO}(3.2 \% \mathrm{O})$ & 70.42 & 0.995 & [34] \\
\hline MWCNTs oxidized by $\mathrm{NaClO}(4.7 \% \mathrm{O})$ & 102.04 & 0.998 & {$[34]$} \\
\hline MWCNTs & 85.61 & 0.963 & {$[37]$} \\
\hline $\mathrm{CNTs}$ refluxed in $\mathrm{HNO}_{3}$ at $140^{\circ} \mathrm{C}$ for $2 \mathrm{~h}$ & 51.81 & 0.992 & {$[38]$} \\
\hline MWCNTs_-polyacrylamide & 29.71 & - & [39] \\
\hline
\end{tabular}

Table 4. Thermodynamic parameters of $\mathrm{Pb}^{2+}$ adsorption onto surface-modified CNTs.

\begin{tabular}{lccc}
\hline$T(\mathrm{~K})$ & $\begin{array}{c}\Delta G^{\mathrm{o}} \\
(\mathrm{J} \mathrm{mol}\end{array}$ & $\Delta H^{\mathrm{o}}\left(\mathrm{kJ} \mathrm{mol}^{-1}\right)$ & $\Delta S^{\mathrm{o}}\left(\mathrm{J}(\mathrm{mol} \mathrm{K})^{-1}\right)$ \\
\hline 283 & -998.52 & 11.56 & 44.00 \\
293 & -1290.86 & & \\
303 & -1583.01 & & \\
313 & -2194.39 & & \\
323 & -2776.54 & & \\
\hline
\end{tabular}

$\left(\Delta G^{\mathrm{o}}\right)$ at different temperatures possessed negative values. This fact shows that $\mathrm{Pb}^{2+}$ adsorption onto modified CNTs is spontaneous and favourable at high temperature. The positive value of standard entropy $\left(\Delta S^{\mathrm{o}}=+44.00 \mathrm{~J} \mathrm{~mol}^{-1} \mathrm{~K}^{-1}\right)$ demonstrated that the adsorption enhances the chaotic level of system because the number and kind of ions increase in the solution after adsorption. Thermodynamic nature of this adsorption is similar to $\mathrm{Cu}^{2+}$ adsorption by oxidized multiwalled CNTs [26].

\section{Conclusions}

CNTs modified by the mixture of $\mathrm{HNO}_{3}$ and $\mathrm{H}_{2} \mathrm{SO}_{4}$ acids are a good sorbent useful for removal of $\mathrm{Pb}^{2+}$ ions from aqueous solution. The suitable condition for modifying CNTs were $50^{\circ} \mathrm{C}, 5 \mathrm{~h}, \mathrm{HNO}_{3}$ and $\mathrm{H}_{2} \mathrm{SO}_{4}$ concentration of 13 and $58.80 \%$, respectively. Isotherm data exhibited that the Langmuir model described the adsorption well; the maximum adsorption capacity was found to be $100.00 \mathrm{mg} \mathrm{g}^{-1}$. The chemisorption nature was demonstrated by a pseudo-secondorder rate model and the sorption reached equilibrium after $80 \mathrm{~min}$. The negative Gibbs free energy variation $\left(\Delta G^{\circ}\right)$ and positive calorific energy $\left(\Delta H^{\circ}\right)$ in the range of temperature from 10 to $50^{\circ} \mathrm{C}$ showed that the adsorption was a spontaneous and endothermic process. The ion exchange mechanism of $\mathrm{Pb}^{2+}$ removal was proved through positive entropy variation $\left(\Delta S^{\#}\right)$, activation energy $\left(E_{\mathrm{a}}\right)$ or activation enthalpy $\left(\Delta H^{\#}\right)$, $\mathrm{pH}$ and electrical conductivity values of $\mathrm{Pb}^{2+}$ solution before and after adsorption.

\section{References}

[1] Dumčius A, Paliulis D and Kozlovska-Kędziora J 2011 Ekologija 5730

[2] Rahman S, Khan M T R, Akib S and Biswwas S K 2013 Pensee J. 10421

[3] Elsehly E M I, Chechenin N G, Makunin A V, Vorobyeva E A and Motaweh H A 2015 Int. J. N. Technol. Sci. Eng. 214

[4] Moosa A A, Ridha A M and Abdullha I N 2015 Int. J. Innov. Res. Sci. Eng. Technol. 4275

[5] Peng X, Jia J and Luan Z 2009 J. Chem. Technol. Biotechnol. 84275

[6] Stafiej A and Pyrzynska K 2007 Sep. Purif. Technol. 5849

[7] Datsyuka V, Kalyvaa M, Papagelisb K, Partheniosa J, Tasisb D, Siokoua A et al 2008 Carbon 46833

[8] Yoon S M, Kim S J, Shin H J, Benayad A, Choi S J, Kim K K et al 2008 J. Am. Chem. Soc. 1302610

[9] Zehua Q and Guojian W 2012 J. Nanosci. Nanotechnol. 12105

[10] Farbod M, Tadavani S K and Kiasat A 2011 Colloids Surf. A 384685

[11] Romanos G E, Likodimos V, Marques R R N, Steriotis T A, Papageorgiou S K, Faria J L et al 2011 J. Phys. Chem. C 115 8534

[12] Tobias G, Shao L D, Ballesteros B and Green M L H $2009 \mathrm{~J}$. Nanosci. Nanotechnol. 96072

[13] Kitamura H, Sekido M, Takeuchi H and Ohno M 2011 Carbon 493851

[14] Rosca I D, Watari F, Uo M and Akaska T 2005 Carbon 433124

[15] Yu H, Jin Y G, Peng F, Wang H J and Yang J 2008 J. Phys. Chem. C 1126758 
[16] Marques R R N, Machado B F, Faria J L and Silva A M T 2010 Carbon 481515

[17] Paula A J, Stefani D, Souza Filho A G, Kim Y A, Endo M and Alves O L 2011 Chemistry 173228

[18] Atieh M A, Bakather O Y, Al-Tawbini B, Bukhari A A, Abuilaiwi F A and Fettouhi M B 2010 Bioinorg. Chem. Appl. 2010603978

[19] Li Y H, Wang S, Wei J, Zhang X, Xu C, Luan Z et al 2002 Chem. Phys. Lett. 357263

[20] Mubarak N M, Thobashinni M, Abdullah E C and Sahu J N 2016 Carbon 27

[21] Xu D, Tan X, Chen C and Wang X 2008 J. Hazard. Mater. 154 407

[22] Ciobotaru C C, Damian C M and Iovu H 2013 UPB Sci. Bull. $B 75$

[23] Cravotto G, Garella D, Gaudino E C, Turci F, Bertarione S, Agostini G et al 2011 New J. Chem. 35915

[24] Scheibe B, Borowiak-Palen E and Kalenczuk R J 2010 Mater. Charact. 61185

[25] Li Y H, Luan Z, Xiao X, Zhou X, Xu C, Wu D et al 2003 Adsorpt. Sci. Technol. 21475

[26] Wang J, Li Z, Li S, Qi W, Liu P, Liu F et al 2013 Plos One 8
[27] Sui X-M, Giordani S, Prato M and Wgner H D 2009 Appl. Phys. Lett. 9233113

[28] Li Y H, Di Z C, Luan Z K, Dinh J, Zuo H, Wu X Q et al 2004 J. Environ. Sci. 16208

[29] Sheng G, Li J, Shao D, Hu J and Chen C 2010 J. Hazard. Mater. 178333

[30] Tehrani M S, Azar P A, Namin P E and Dehaghi S M 2013 J. Environ. Protect. 4529

[31] Regina L M 1993 J. Environ. Health 5611

[32] U.S. Environmental Protection Agency 2008 Document no. EPA 816-F-08-018 Washington, DC: EPA

[33] Srivastava S 2013 Adv. Mater. Lett. 42

[34] Yu F, Wu Y, Ma J and Zhang C 2013 J. Environ. Sci. 24195

[35] Anirudhan T S and Radhakrishnan P G 2008 J. Chem. Thermodyn. $\mathbf{4 0} 702$

[36] Kan C C, Aganon M C, Futalan C M and Dalida M L P 2013 J. Environ. Sci. 251483

[37] Rahbari M and Goharrizi A S 2009 Water Environ. Res. 81598

[38] Wang H J, Zhou A L, Peng F, Yu H and Chen L F 2007 Mater. Sci. Eng. A 466201

[39] Yang S, Hu J, Chen C, Shao D and Wang X 2011 Environ. Sci. Technol. 453621 